\title{
A Methodology for Exploring, Documenting, and Improving Humanitarian Service Learning in the University
}

\author{
Devin R. Berg \\ Department of Engineering and Technology \\ University of Wisconsin-Stout, Menomonie, Wisconsin, USA \\ bergdev@uwstout.edu \\ Tina Lee \\ Department of Social Science \\ University of Wisconsin-Stout, Menomonie, Wisconsin, USA \\ leetina@uwstout.edu \\ Elizabeth A. Buchanan \\ Center for Applied Ethics \\ University of Wisconsin-Stout, Menomonie, Wisconsin, USA \\ buchanane@uwstout.edu
}

\begin{abstract}
Through the use of service learning in higher education, universities hope to both provide real benefit to the partnering community and allow students to develop a greater understanding of course curriculum, their discipline, and their personal positioning within society. Through these educational activities, service learning seeks to engage students in critical thinking processes whilst simultaneously achieving a greater sense of civic and social responsibility through targeted participation in meaningful community service activities. However, in practice, service learning can take a variety of forms predicated on technical, cultural, societal, and political constraints. Thus, while some work shows positive effects on students' attitudes, social behaviour, and academic performance, less research has demonstrated long-term community impact. Nor has much research shown that participation in service learning has a long-term impact on students' ethical perspectives and frameworks, and whether those ethical frames carry on to their professional careers. Moreover, as institutions partner with such humanitarian service groups as Engineers Without Borders USA, we know considerably less about the institutional cultures and climates that are developed through such partnerships and how sustainable they are, given those inherent technical, political and cultural limitations. As a first step towards these goals, this paper proposes a methodology for investigating the impacts of service learning activities on both the students and communities involved.
\end{abstract}

KEYWORDS: Service learning, humanitarian engineering, professional ethics, critical enquiry, curriculum development

\section{INTRODUCTION}

Service learning (SL) has been one strategy used across educational institutions, with a common goal of promoting civic engagement. Some examples include Engineers Without Borders (EWB) or Engineering Projects in Community Service (EPICS) (Coyle, 2005). It is defined as:

"A course-based, credit-bearing educational experience in which the students (a) participate in an organised service activity that meets identified community needs, and (b) reflect on the service activity in such a way as to gain further understanding of course content, a broader appreciation of the discipline, and an enhanced sense of personal values and civic responsibility," (Bringle and Hatcher, 2009).
SL thus seeks to engage students in critical thinking processes while simultaneously achieving a greater sense of civic and social responsibility through targeted participation in meaningful community service activities. However, SL is not without its critics, noting that as a practice, it has inherent technical, cultural and political limitations: Service learning can easily privilege students and teachers at the expense of the communities being served (Butin, 2010). The nature of many SL projects leads to a higher than average likelihood of failure. When project failure does occur it is important to understand the impacts such as has been done by Engineers Without Borders-Ingénieurs Sans Frontiers Canada in their Failure Reports (http://legacy.ewb.ca/en/whoweare/accountable/ failure.html). Given the possibility of failure, it is important to understand the impacts on the collaborating dis- 
advantaged communities. While meta-analyses of SL shows positive effects on students' attitudes, social behaviour, and academic performance (Celio et al., 2011), less research has demonstrated long-term community impact. Nor has much research shown that participation in service learning has a long-term impact on students' ethical perspectives and frameworks, and whether those ethical frames carry on to their professional careers. Moreover, as institutions partner with such humanitarian service groups as EWB, we know considerably less about the institutional cultures and climates that are developed through such partnerships and how sustainable they are, given those inherent technical, political and cultural limitations. In short, does service learning promote and sustain an ethical culture, and if so, how are those ethical cultures promoted and sustained, and for whom are there significant benefits?

Ethics is most broadly understood as a branch of philosophy concerned with matters or morality: determining "right" and "wrong." Ethics is a systematic investigation into moral matters, and has been extended into "professional ethics", where matters of professional behaviours, activities, norms, and practices are investigated. In the engineering professions various associations, for example, the Accreditation Board for Engineering and Technology, the Association for Computing Machinery, the National Society of Professional Engineers, endorse specific codes of ethics and ethical norms and values. Generally, codes of ethics support a specific ethical framework (for example, utilitarianism, consequentialism, deontology). For this paper and its related project, the investigators are purposefully not limiting to a specific ethical framework; as we are working in an international environment, across cultures, value-frameworks, and professional specificity, we will not ascribe a particular ethical frame until data is collected and reviewed. Instead, this project aims to understand the ethical frameworks that students, faculty, and community members bring to EWB projects and how students refine and change their thinking about ethics over time.

As with SL, "engineering to help" (ETH) models have been critiqued from a number of perspectives, coming from development studies, feminist theory and cultural studies (Schneider et al., 2009), while on a pragmatic level, Riley (2008) noted that there has been little attention paid to "past failures", or to preventing future failures, in the ETH literature. Articulating what failure and success mean in SL/ETH has been quite arbitrary across institutions, EWB chapters, and in the SL literature in general; in response, Engineers Without Borders USA (EWB-USA) has recently developed clearer training and preparation guidelines for its chapters and members, and it is also requiring more detailed reporting to better identify the social, ethical, and cultural implications of all EWB-USA projects. Thus, a "successful project" will not only result in a functional tool or process over time, but the impact of a project on a community's culture, ethical frames, and social practices must also be considered. Those individuals engaged in an EWB-USA project must be prepared not just technically, but ethically and socially:

"As the world becomes more complex and interrelated, so do the problems engineers face. The engineering profession and individual engineers need to adapt or else risk getting lost in these global changes, thus abandoning our social responsibilities" (Chan and Fishbein, 2009).

Examining the issues from the perspective of engineering education, it is not surprising that much of the traditional engineering curriculum has been focused on providing solutions to the problems of the world's wealthiest citizens (Amadei, 2014). In response, Amadei's vision of engineering education through SL promotes "a world where all people have access to basic resources and knowledge to meet their self-identified engineering and economic development needs" (Helgesson, 2006). Further, by providing students the opportunity to explore the engineering curriculum as it applies to the challenges of globalisation, population explosion, resource depletion, and so on, we are promoting and contributing to a more socially aware and responsible profession: "Addressing the needs of clean water, sanitation, energy, shelter, etc. is no longer an option for the engineering profession; it is an ethicalobligation. Bothengineering practiceandengineering education need to be considered" (Amadei and Sandekian, 2010). A traditional engineering curriculum, and an institution that does not provide SL opportunities, will likely fail to provide students with the critical skills of cultural engagement necessary to live and work in a globally connected world and profession. According to the 2011 study conducted by the American Society of Mechanical Engineers (ASME) titled "The State of Mechanical Engineering: Today and Beyond," engineers are facing increasing expectations in terms of ability to work across cultures and in a variety of regions around the world, both developed and developing. According to ASME, the two most needed professional skills in the future will be an ability to manage global teams and an ability to speak more than one language. Further, two of the top five most needed personal skills will be a sense of social responsibility and diplomacy. These predicted needs speak strongly to the desire of our stakeholders, in industry and the public, for students who have a multidisciplinary skill set. Students with these skills are likely to be the best prepared for dealing with complex challenges such as the intricacies of globalisation, population increase, and water and resource depletion. What is not clear, however, is if SL and in particular international SL is the best method for developing these skills. Further, if SL is appropriate, it is imperative that the costs and risks carried by the host site are well understood (Vandersteen et al., 2009).

While as noted above, research indicates that SL generally improves student achievement (Celio, 2011), less is known about student reflection and ethical engagement in SL. However, in a limited study, Johnston et al. (2007) looked 
specifically at environmental engineering students in relation to EWB-USA:

"At the end of a three-week EWB-USA project, students were asked to respond to questions targeting their understanding of social and environmental issues before and after the project. Approximately 380 students submitted a completed questionnaire. Of the students responding, $63.2 \%$ felt that they knew little about global social and environmental issues prior to the EWB-USA project. After completing the EWBUSA project $72.5 \%$ of those students felt they had significantly improved their knowledge. Additionally, $14.5 \%$ of respondents felt they had some knowledge of environmental issues prior to the project. Interestingly, $50.1 \%$ of those students still felt the EWB-USA project had improved their understanding. Overall, almost $70 \%$ of students responded that they had improved their social and environmental awareness after completing a three-week EWB-USA project."

All of this highlights a greater need for a deeper understanding of the impacts of SL on students and the implications on the other stakeholders involved in such activities. The authors intend to extend this limited research through a comprehensive and collaborative investigation of service learning activities such as participation in EWB projects. This paper presents the first step in the process which is to define a methodology by which this investigation can be carried out.

\section{RESEARCH CONTEXT}

\subsection{Meshing with the Spirit of a Polytechnic: A} Case Study at UW-Stout

The University of Wisconsin-Stout is situated in northern Wisconsin and was designated "Wisconsin's Polytechnic University" in 2007 by the University of Wisconsin Board of Regents. Stout's institutional mission (University of Wisconsin-Stout, n.d.) encourages faculty and staff to "integrate applied learning, scientific theory, humanistic understanding, creativity and research to solve real-world problems, grow the economy and serve a global society." The university offers professional, career-focused programs in the arts, social and related sciences, engineering, education, natural sciences and technology. With the polytechnic designation comes an increased focus on applied learning techniques and career focused curriculum. If we are to achieve the tenets of a polytechnic institution then it is important to both understand what skills employers seek from our graduates as well as the pedagogical methods we can employ to best achieve these skills. Further, what constraints are present which may limit the adoption and influence on the outcomes achieved in the institution's graduates? For example, it is important to first ensure that both the instructors and the students make the connection between personal and professional views of their own social, environmental, and ethical obligations (Canney
\& Bielefeldt, 2015). Within the context of a polytechnic institution, the career-focused curriculum can lead students to have a narrow view of what curriculum is relevant to their careers. As previously mentioned, ASME's report points to the desire within industry to hire students well prepared to work in a global, cross-cultural environment. For this reason it is important to understand if participation in SL better prepares students for this sort of work environment and in what ways is SL successful or not successful in developing these skill sets. It is within this context that the authors hope to study the influence of SL on the students' awareness and connection to social and environmental issues as well as the ethical frameworks they develop and carry with them into their professional careers.

At UW-Stout, the concept of service learning has been applied in a variety of ways ranging from local community service built into the course curriculum to independent service trips to local, regional, and international destinations. The opportunities available to engineering students generally consist of volunteered time working on Habitat for Humanity projects, competing in independent, externally sponsored design competitions with a humanitarian focus, or two to three week trips to participate in project work. Towards our mission of applied learning and humanistic understanding, recently, UW-Stout initiated a chapter of EWB-USA. Housed in the department of Engineering and Technology, in the College of Science, Technology, Engineering, and Mathematics, undergraduate students now have the opportunity to join the EWB-USA chapter as it begins to plan its first community-based clean water project in Nicaragua. The impetus for this decision was motivated by student interest and a desire to provide students with the opportunity to make a positive impact in the lives of others. This development provides the opportunity to study the impacts of participation in SL, such as through an EWBUSA chapter, from the chapter's inception.

\subsection{Research Questions}

As part of this study into the impacts of SL, the work is being framed around the three primary research questions articulated below.

1. Does participation in service learning such as EWB contribute to a culture of ethical professional practice? Do participants from SL projects experience their education in a qualitatively different way than those who do not? Are these students more culturally sensitive or globally aware?

2. How can we learn from the on-ground experiences of students and faculty to identify and promote best practices in humanitarian SL for more ethically aware graduates?

A. How does participation in SL "fit" into the typical practices of undergraduates? How interconnected is the social responsibility element of SL to the totality 
of their educational experiences?

B. If students are not able to experience a project from inception to conclusion, including seeing the longerterm impacts of their work, are their experiences less meaningful? What are the professional responsibilities that students miss by participating in only some segments of a project?

C. How can institutions encourage meaningful participation for faculty and students? What does that participation resemble, and what are the short and long-term effects of participation in international SL work through EWB?

D. How do we ensure participation in international SL activities on university campuses is driven by an ethical imperative and is a sustainable benefit for the communities being served?

E. What institutional constraints face both faculty and student participants in EWB chapters? What commonalities exist across institutions and what strategies can we develop to minimise such constraints for the betterment of SL?

3. Who is the primary client or beneficiary of SL? What is the balance between helping a community versus, or contrasted to, student experiences?

\section{METHODOLOGY}

This section sketches the author's proposed research methodology for an investigation of the research questions outlined in Section 2. It was developed to make use of data and resources available to the authors, so we only discuss it briefly and then note how it can be adapted for broader application by those who wish to carry our similar studies in Section 5.

\subsection{Data Collection and Analysis}

1. Ten years of project data including proposals, assessment reports, and project conclusion reports will be collected from EWB-USA, sampled to get a range of projects illustrative of geographic, temporal, and institutional diversity, and analysed. These will be qualitatively coded to look for trends, patterns, and insights around the success and/or failure of projects in terms of benefits for students and communities.

2. EWB-USA will distribute surveys to its national membership and will organise focus groups at its annual meeting. Questions will focus on views of service learning, experiences with the practice, ethical frameworks and how they were developed and changed over time, ideas about their roles in the communities they work with, and how they judge the success/failure of projects.

3. We will examine the UW-Stout's EWB-USA chapter from its inception through the implementation and assessment of its first project. Stout's chapter was recently launched and is now beginning its first project, so we have the unique opportunity to analyse the project from multiple viewpoints and to see it evolve over time. There are multiple layers to this analysis:

A. We will assess student development and engagement over the course of their EWB-USA experience. We will begin by gathering baseline data from each student as they join the project. From there we will collect data at regular intervals during each student's involvement (upon returning from fieldtrips, for example) and as their involvement ends. Data will be collected through both surveys and interviews throughout the five year project time frame. Questions will focus on student's perceptions of service learning, their ethical responsibilities as professional engineers, their possible growth in their ethical thinking, and their experiences with the project.

B. We will engage in ethnographic field work when the UW-Stout chapter begins its visits to Nicaragua. While EWB-USA provides ample cultural relevance training for its chapters, the reality of field work is unpredictable. Students may be highly prepared for the technical elements of their projects, but not the socio-ethical challenges and opportunities. Social science students (under the supervision of Dr. Lee, a cultural anthropologist) will investigate the onground experiences of service learning participants by collecting ethnographic data through participant observation and interviewing. This data will be used to both gauge student development as they undertake the project and evaluate the effectiveness of training with the aim of providing suggestions for improvement.

C. In order to gather comparison data, the Engineering and Technology department will also survey its nonEWB-USA participants around their perceptions of SL projects, social responsibility in their discipline, and ethics in STEM. These questions will also be used to gather data about what sort of SL projects students have participated in previously. This will provide an understanding of why students choose not to participate and allow us to see if these students show any change in their awareness of ethical issues and ethical practices throughout their four-year university experience without having participated in the EWB project.

4. We will assess the impacts of UW-Stout's EWB chapter's first project on the host community in Nicaragua through ethnographic fieldwork. Social Science students will observe interactions and collaborations between EWB students/faculty and community members. They will also interview community members about their experiences and the impacts they see as the project progresses. As the project concludes, a survey of community members will also be undertaken to measure how satisfied 
they were with the project and how it impacted their community.

5. In addition to studying the UW-Stout chapter students, EWB-USA will identify 3-5 other chapters who are also in the inception stage, and these chapters will be monitored and assessed for the next five years, through a comparative case study approach. We will gather the same data from those chapters.

\subsection{Survey Instruments}

We will adapt the Sustainability Skills and Dispositions Scale (SSDS) (Hess et al., 2015) for use in our project. This instrument asks students to rate themselves in terms of their confidence in technical design and in working with communities and measures their sense of their responsibilities as professionals in global, social and environmental contexts. We will also include some items from the Engineering Professional Responsibility Assessment (Canney, et al., 2015). This survey asks students to rate to what degree their professional responsibilities include such things as volunteering, doing pro bono work, or changing designs with input from communities. Finally, some questions from the ethnocentrismscale developed by Neuliep and McCroskey (1997) will be included. This survey measures attitudes towards cultural differences and will be useful in seeing if students grow in their knowledge of and attitude towards the differences they encounter when designing engineering solutions in a different culture.

Additional questions are necessary which focus on where ethical concepts (respect for cultural difference, sustainability, etc.) are taught in their university curriculum. Follow-up surveys will include qualitative questions that ask students to reflect on how their experience in EWB-USA contributed to their thinking about sustainability, awareness of global issues, ability to work with communities, and so on. Finally, we will collect basic demographic information (race/ethnicity, gender, class).

\section{INTENDED OUTCOMES}

\subsection{Adaptation of EWB-USA Program Guidelines}

The case study of UW-Stout's progression as a chapter from inception to project engagement will provide a resource for other institutions interested in EWB-USA and the concomitant ethical challenges raised by service learning and humanitarian initiatives at the university level. Whilst EWB-USA has succinct policies in place for its members and those interested in engaging with a community, our case study will reveal the intricacies of institutional constraints, administrative challenges to long-term projects, fostering and sustaining student engagement over the project span, and fostering a culture across STEM disciplines around social responsibility and ethical reasoning. Moreover, based on the in-depth data analysis of EWB-USA projects, and the accompanying data from relevant stakeholders, the intimate collaboration between UW-Stout and EWB-USA will result in a set of robust guidelines and recommendations around academic service learning initiatives such as EWB-USA. EWB-USA is continually seeking improvements to its program, and agency specific guidance around service learning and academic institutions would contribute to the organisation's success.

\subsection{Curriculum Integration}

In addition, this project will enable us to reflect on and develop ways to build and enhance engineering and technology education. Based on findings generated from the project, we will develop a new undergraduate course on Global Engineering, which will further solidify the connections between the fields of Engineering and Technology, Social Science, and Ethics. The new course will benefit from this study's in-depth analysis of service learning and the impact on students and communities. Chan and Fishbein (2009) refer to the "global engineer" as one with a defined sense of social responsibility and ethics, entrepreneurism, and the ability to deal with complexity and systems thinking. The new junior level Global Engineering course will possibly be offered as a university general education course, and included as an elective for all engineering and technology and social science students. Through this course, we are meeting the call to "integrate development or critical studies in the required curricula for students working with 'underserved' communities. Humanities scholars, social scientists, and engineers who teach in and coordinate these programs should instill in students a sense of long-term responsibility towards their ... projects by challenging them to explore long-term evaluation of current and past projects and to learn from past successes and failures" (Schneider, 2009).

\section{RECOMMENDATIONS}

Our overall methodology takes advantage of a unique opportunity to partner with EWB-USA, and we hope it will provide rich data about best practices in service learning humanitarian engineering projects. However, there is much to be gained from adapting this research methodology to study additional EWB chapters, and other similar organisations, as UW-Stout is not necessarily representative of most institutions. With this in mind, the authors believe that aspects of our methodology are broadly applicable and, indeed, vital for fully understanding how engineering service learning works, how it benefits students and communities, and how it can be expanded and improved. For others who wish to conduct similar case studies, or for those who would like to assess ongoing projects, we would suggest that a mixed-methods approach is important. Collecting student's self-reports of how their views have been shaped by their involvement in humanitarian engineering service learning projects, coupled with at least some observation of ongoing projects by outsiders, including interactions with students and the communities 
being served, we argue, provides a robust methodology for understanding the effectiveness of service learning projects. Utilising both qualitative data and quantifiable measures of student attitudes and growth provides rich material for a deeper understanding.

We would thus suggest:

- Pre-test surveys to measure student views on ethics, global awareness, ethical understandings, and their roles as professionals.

- Follow-up surveys and interviews with students at each stage of their involvement and upon completion.

- Observations of service learning projects in the field.

- Data collection (quantitative and/or qualitative as possible) with a comparison group of students.

\section{CONCLUSION}

Service learning provides an opportunity to expose students to projects and work intended for the mutual benefit of society through the promotion of civic engagement. However, due to the varied methods by which SL is employed in higher education, it is not always clear that students are indeed graduating after participation in these activities with any long-term impact on their social or environmental perspectives and ethical frameworks, and whether those qualities carry on to their professional careers. Further, there is some question as to whether $\mathrm{SL}$, as it is used in higher education today, consistently provides clear benefit to the communities involved or if those communities are being exploited in the pursuit of better education for the privileged constituents of the university.

It is the hope of the authors that scholars involved with the use of SL in higher education can adapt the methodology proposed here to evaluate their own practices to ensure that not only are their students experiencing meaningful change in the professional outlooks but that the partnering communities are also benefitting from the sort of relationships found in typical service learning activities. Further, as the study progresses, the authors believe that new guidelines for the implementation of SL in higher education will be developed to aid other institutions. Finally, the development of course curriculum grounded in this work will be disseminated as a means of further integrating SL and to aid the development of the 'global engineer'.

\section{7}

\section{REFERENCES}

Amadei, B., 2014, Engineering for sustainable human development, American Society of Civil Engineers, Reston, Virginia, USA.

Amadei, B. \& Sandekian, R., 2010, 'Model of integrating humanitarian development into engineering education',
Journal of Professional Issues in Engineering Education and Practice, vol. 136, no. 2, pp. 84-92. doi: 10.1061/ (ASCE)EI.1943-5541.0000009

Bringle, R. G. \& Hatcher, J. A., 2009, 'Innovative practices in service: learning and curricular engagement,' New Directions for Higher Education, vol. 147, pp. 37-46. doi: 10.1002/he.356

Butin, D., 2010, Service-learning in theory and practice, Palgrave McMillan, New York, NY, USA.

Canney, N. \& Bielefeldt, A., 2015, 'A framework for the development of social responsibility in engineers', International Journal of Engineering Education, vol. 31, no. 1B, pp. 414-424.

Canney, N.E., Bielefeldt, A. \& Russu, M., 2015, 'Which courses influence engineering students' views of social responsibility', American Society for Engineering Education (ASEE) Annual Conference and Exposition Proceedings, 14-17 June 2015. Seattle, WA, USA.

Celio, C. I., Durlak, J., \& Dymnicki,A., 2011, 'Ameta-analysis of the impact of service-learning on students', Journal of Experiential Education, vol. 34, iss. 2, pp. 164-181, doi: $10.1177 / 105382591103400205$

Chan, A. \& Fishbein, J., 2009, 'A global engineer for the global community,' The Journal of Policy Engagement, vol. 1, pp. 4-9.

Coyle, E., Jamieson, L., \& Oakes, W., 2005, 'EPICS: Engineering projects and community service', International Journal of Engineering Education, vol. 21, pp. 139-150.

Failure Reports, n.d., Engineers Without Borders-Ingénieurs Sans Frontières Canada. Available from http://legacy.ewb. $\mathrm{ca} / \mathrm{en} /$ whoweare/accountable/failure.html

Helgesson, C., 2006, 'Engineers Without Borders and their role in humanitarian relief', Engineering in Medicine and Biology Magazine, vol. 25, pp. 32-35, doi:10.1109/ MEMB.2006.1636348

Hess, J. L., Brownell, S. A., House, R. A., \& Dale, A. T., 2015, 'Development and application of the sustainability skills and dispositions scale to the wicked problems in sustainability initiative', American Society for Engineering Education (ASEE) Annual Conference and Exposition Proceedings, 14-17 June 2015. Seattle, WA, USA.

Johnston, C., Caswell, D., \& Armitage, G., 2007, 'Developing environmental awareness in engineers through Engineers Without Borders and sustainable design projects', International Journal of Environmental Studies, vol. 64, pp. 501-506, doi: 10.1080/00207230701382198

Neuliep, J. W. \& McCroskey, J. C., 1997, 'The development of a US and generalized ethnocentrism scale', Communication Research Reports, vol. 14, no. 4, pp. 385-398, doi: 10.1080/08824099709388682

Riley, D., 2008, Engineering and Social Justice. Morgan \& Claypool, San Rafael, CA, USA. 
Schneider, J., Lucena, J., \& Leydens, J., 2009, ‘Engineering to help: The value of critique in engineering service', Technology and Society Magazine, vol. 28, no. 4, pp. 42-48, doi: 10.1109/MTS.2009.935008

American Society of Mechanical Engineers, 2011, 'The state of mechanical engineering: today and beyond', pp. 1-23, <www.asme.org/getmedia/752441b6-d335-4d939722-de8dc47321 de/State-of-Mechanical-EngineeringToday-and-Beyond.aspx $>$
University of Wisconsin-Stout, n.d., UW-Stout Mission, Vision and Values, <www.uwstout.edu/about/mission.cfm> VanderSteen, J. D. J., Baillie, C., \& Hall, K., 2009, 'International humanitarian engineering,' IEEE Technology and Society Magazine, vol. 28, no. 4, pp. 32-41, doi: 10.1109/MTS.2009.934998 